\title{
Laboreal
}

Volume $4 \mathrm{~N}^{\circ} 2$ | 2008

A inovação

\section{Quando o projeto participativo de espaços de trabalho se encontra com o projeto de engenharia em eventos de colaboração mútua}

Cuando el proyecto participativo de espacios de trabajo se encuentra con el proyecto de ingeniería en eventos de colaboración mutua

Quand la conception participative des espaces de travail rencontre le projet d'ingénierie en évents collaboratives

When participatory workspace design meets engineering design in collaborative events

\section{Ole Broberg}

Tradutor. Francisco Moura Duarte e Carolina Souza

\section{(2) OpenEdition}

\section{Journals}

\section{Edição electrónica}

URL: http://journals.openedition.org/laboreal/11197

DOI: 10.4000/laboreal. 11197

ISSN: 1646-5237

Editora

Universidade do Porto

\section{Refêrencia eletrónica}

Ole Broberg, "Quando o projeto participativo de espaços de trabalho se encontra com o projeto de engenharia em eventos de colaboração mútua », Laboreal [Online], Volume 4 №2 | 2008, posto online no dia 01 dezembro 2008, consultado o 10 outubro 2019. URL : http://journals.openedition.org/ laboreal/11197; DOI : 10.4000/laboreal.11197

Este documento foi criado de forma automática no dia 10 outubro 2019.

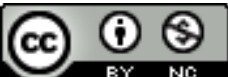

Laboreal está licenciado com uma Licença Creative Commons - Atribuição-NãoComercial 4.0 Internacional. 


\section{Quando o projeto participativo de espaços de trabalho se encontra com o projeto de engenharia em eventos de colaboração mútua}

Cuando el proyecto participativo de espacios de trabajo se encuentra con el proyecto de ingeniería en eventos de colaboración mutua

Quand la conception participative des espaces de travail rencontre le projet d'ingénierie en évents collaboratives

When participatory workspace design meets engineering design in collaborative events

\section{Ole Broberg}

Tradução : Francisco Moura Duarte e Carolina Souza

\section{NOTA DO EDITOR}

Manuscrito recebido em : Setembro/2008

Aceite após peritagem em : Novembro/2008

o Programa de Pesquisa de Projeto do Espaço de Trabalho é parcialmente financiado pela Fundação Dinamarquesa de Pesquisa em Ambiente de Trabalho.

\section{Introdução}

Muitos ergonomistas e outros profissionais do local de trabalho são alocados em posições de consultoria, como o serviço de saúde ocupacional (OHS - Occupational Health Service) na Dinamarca. O OHS na Dinamarca passou recentemente por uma 
grande mudança, deixando de ser um sistema obrigatório para as empresas, e passando a ser um sistema que opera em um mercado liberalizado. Ao longo dos anos, um objetivo importante para as unidades do OHS foi o de sempre buscar ser proativo, tentando integrar aspectos de segurança e saúde na fase de projeto de transformações sócio-técnicas nos locais de trabalho. Entretanto, ao lidar com esses processos de mudança em empresas clientes, a experiência mostrava a dificuldade frequente do consultor OHS para ter acesso e influenciar o processo de projeto de um ponto de vista ergonômico. Em um estudo anterior foi mostrado que a habilidade de assumir o papel de um "navegador político e reflexivo" pode ser um fator de sucesso em tais situações (Broberg \& Hermund, 2004). Entretanto, ao invés de tentar "forçar" a ergonomia no processo de projeto, os ergonomistas poderiam assumir outro papel. 0 papel de "projetista do espaço de trabalho" pode ser uma nova abordagem para integrar a ergonomia nos processos de projeto. Nesse papel, o ergonomista assume uma abordagem mais orientada para o projeto, com um foco na condução do processo de projeto do espaço de trabalho. Isso pode contribuir para superar alguns dos obstáculos relacionados à integração da ergonomia na concepção (Broberg, 2007). Pode ainda, além disso, ser um novo serviço oferecido pelas unidades liberalizadas do OHS, muitas das quais absorvidas pelas empresas de consultoria em engenharia.

O programa de pesquisa do Projeto de Espaços de Trabalho (WSD - Workspace Design) da Dinamarca visa desenvolver e experimentar tal conceito que é potencialmente novo para ergonomistas e consultores do OHS envolvidos em processos de projetos que implicam em espaços de trabalho novos ou transformados. A noção de projeto de espaço de trabalho é inspirada no trabalho de Horgen (Horgen, Joroff, Porter \& Schön, 1999). O local de trabalho com práticas de trabalho é visto como inserido em quatro dimensões (Figura 1) : espacial, organizacional, financeira e tecnológica (SOFT - Spatial, Organizational, Financial, Technological). 


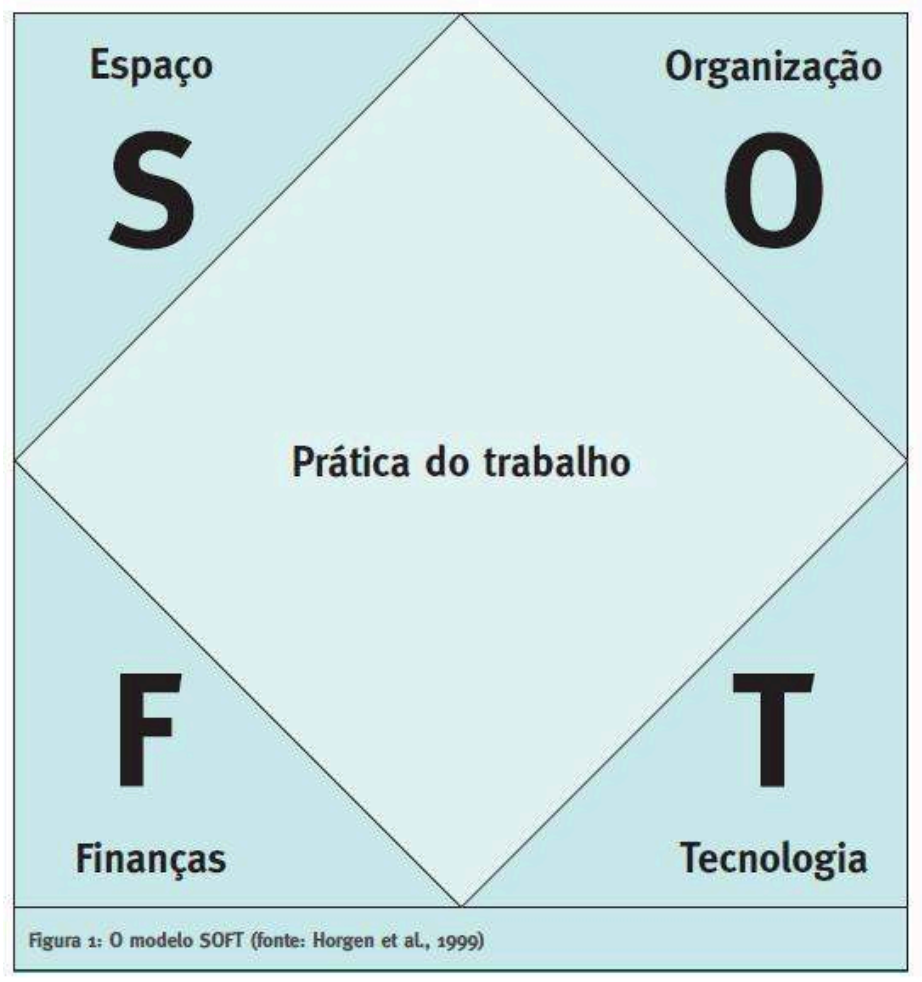

3 Essas dimensões são interdependentes e se relacionam de forma dinâmica. Uma mudança numa dimensão pode demandar igualmente mudanças em outras. A encenação do processo de projeto do espaço de trabalho tem por objetivo a criação de uma coerência dinâmica entre o trabalho e estas quatro dimensões do espaço de trabalho. A criação e modelagem de locais de trabalho são processos influenciados pelos atores que preenchem cada uma das quatro dimensões. A idéia básica do conceito de projeto do espaço de trabalho aponta para a necessidade de atores que sejam capazes de trabalhar através dos quatro ângulos, facilitando e negociando o processo de construção do espaço. Esses atores encenam o processo de projeto : eles são projetistas do espaço de trabalho. Este é um trabalho de criar visões compartilhadas entre os atores com diferentes perspectivas e competências, superando resistências e interesses políticos, estabelecendo um processo de projeto colaborativo e facilitando reuniões entre atores dos diferentes vértices do modelo SOFT.

Some-se a isso, uma característica central do conceito de projeto do espaço de trabalho : a encenação do processo de concepção é baseada na participação dos usuários [1]. Isso implica que metodologias e ferramentas para a participação dos usuários são importantes elementos do conceito. Finalmente, o conceito é voltado para ajudar as organizações a criar locais de trabalho eficientes e sólidos, isto é, condições de trabalho saudáveis, seguras e ergonômicas.

5 Tendo delineado os objetivos e características básicas do projeto do espaço de trabalho, é claro que o programa se soma às abordagens de projeto centradas no usuário ou centradas no ser humano, abordagens estas que tentam intervir no projeto a fim de construir tecnologias mais ergonômicas, amigáveis e "humanas". Em linha com Badham, Garrety e Kirsh (2001) e Garrety e Badham (2004), argumenta-se pela necessidade do entendimento do contexto político e organizacional que cerca tais 
intervenções e projetos socio-técnicos. É importante delinear e entender o papel de pesquisadores (de ação) em contextos sócio-técnicos particulares, na medida em que estamos contribuindo para o processo de projeto da tecnologia. A maneira como vendemos os projetos de intervenção para as organizações apresentam conseqüências sobre a maneira de como somos percebidos no campo e, portanto, sobre os resultados da intervenção (Jensen, 2006).

Badham et al. (2001) relatam uma intervenção na pilotagem de um projeto de sistema de produção inteligente. Eles focam nos contextos político e organizacional particulares da intervenção, e observam que tem havido, surpreendentemente, poucos estudos detalhados de tais dimensões. Devido ao contexto político e organizacional, mesmo com a utilização de métodos próprios do projeto centrado no usuário (UCD - User Centred Design), este projeto nunca alcançou um estágio de intervenção com impacto direto no projeto da tecnologia (Garrety \& Badham, 2004). Assim, outro aspecto importante não é relatado: trata-se, em especial, de como e por quais mecanismos os métodos UCD atuam na prática e de como eles podem contribuir para o projeto de engenharia.

7 No programa de pesquisa do WSD, as intervenções em dois casos experimentais tiveram a forma de workshops inspirados em métodos escandinavos de projeto participativo (Greenbaum \& Kyng, 1991 ; Brandt \& Messeter, 2004 ; Johansson, Fröst, Brandt, Binder \& Messeter, 2002). Desta forma, o como "transmitir" e manter insights e resultados dos workshops ao longo do projeto sócio técnico de mudança tornaram-se questões importantes.

O objetivo deste trabalho é relatar o experimento do conceito de projeto do espaço de trabalho num caso envolvendo o projeto e a implementação de uma nova tecnologia em instalação industrial. As questões da pesquisa deste estudo foram: 1) Como os workshops do WSD contribuíram para o processo de projeto de engenharia? 2) Como são transmitidos e mantidos, ao longo do processo de projeto de engenharia, os insights e idéias dos workshops ? 3) Que tipo de ferramentas são necessárias a um projetista do espaço de trabalho?

\section{Abordagem de pesquisa e o papel dos pesquisadores}

O teste do conceito de Projeto do Espaço de Trabalho (WSD) se deu em três empresascaso. Neste trabalho apresento a análise de um caso de produção industrial no qual a empresa iria implementar uma nova tecnologia em sua linha de produção. A equipe do WSD consistiu de três pesquisadores da Universidade Técnica da Dinamarca (Technical University of Denmark), dois consultores do Instituto Tecnológico Dinamarquês (Danish Technological Institute), dois pesquisadores do Centro de Pesquisa em Projeto (Centre for Design Research) e dois consultores do OHS da unidade que normalmente serve o produtor industrial. Essa equipe tentou ficar com o papel de projetista do espaço de trabalho em relação ao processo de mudança tecnológica. A equipe foi parcialmente dividida em pesquisadores intervencionistas e pesquisadores de acompanhamento do processo. O primeiro grupo ficou responsável pelo planejamento e realização das atividades voltadas para o início de um processo de projeto participativo na empresa, de forma a otimizar a ergonomia e a eficiência na unidade de produção que estava sendo projetada. 0 outro grupo ficou responsável pelo estabelecimento de dados de referência em : características básicas da empresa, sistema atual de produção, inclusão da ergonomia, percurso do processo de projeto até o momento, e nível de segurança 
ocupacional e gerenciamento da saúde. Este grupo também observou as intervenções e fez as entrevistas de acompanhamento do processo com os participantes, de modo a esclarecer os efeitos da intervenção.

Os consultores do OHS fizeram parte do primeiro grupo. Dessa forma, o novo papel em potencial do consultor do OHS foi desenvolver um processo de aprendizagem mútua. A idéia era que as atividades planejadas e completadas nesse grupo fossem feitas pelos consultores do OHS em suas atividades futuras junto às empresas.

\section{Encenando o processo de concepção do espaço de trabalho}

11 A idéia básica no programa de pesquisa do WSD era experimentar o papel de projetista do espaço de trabalho em projetos de mudança sócio-técnica dentro de diferentes organizações. Tínhamos uma idéia teórica deste papel baseada no modelo SOFT, e tínhamos uma coleção existente de métodos baseados na experiência adquirida pela equipe dos membros do WSD em seus trabalhos anteriores. Entretanto, foi durante os estudos de caso da intervenção que ganhamos experiência em como praticar esse papel e usar os métodos em contextos organizacionais e tecnológicos particulares. Baseados na experiência acumulada nesses dois estudos de caso, desenvolvemos um modelo para o projetista do espaço de trabalho intervir em projetos de mudança sócio-técnica (figura 2). Nesse modelo, o projetista do espaço de trabalho é visto navegando concomitantemente em três diferentes fases.

Figura 2 : As fases do projeto do espaço de trabalho

\begin{tabular}{|c|c|c|}
\hline $\begin{array}{l}\text { NEGOCIAÇÃO DAS CONDIÇŌES } \\
\text { - O que está em aberto no } \\
\text { SOFT? } \\
\text { - Objetivos da intervençào? } \\
\text { - Recursos? } \\
\text { - Quem deve participar? } \\
\text { - Como transmitir e manter } \\
\text { os resultados dos workshops }\end{array}$ & & $\begin{array}{l}\text { INTERVENC̆Ão } \\
\text { - Workshop } 1 \\
\text { - Trabalho de casa } \\
\text { - Workshop } 2 \\
\text { - Trabalho de casa } \\
\text { - Workshop } 3\end{array}$ \\
\hline & $\begin{array}{l}\text { SISTEMA DE TRABALHO } \\
\text { - Prática de trabalho atual } \\
\text { - Problemas no trabalho e } \\
\text { na organização }\end{array}$ & \\
\hline
\end{tabular}

Ao negociar as condições para a encenação, o projetista do espaço de trabalho investiga e negocia os enquadramentos e redes de comunicação que circundam o projeto de mudança sócio-técnica na organização. Isso será tipicamente baseado em reuniões com 
representantes da gerência e dos trabalhadores. Tendo o modelo SOFT em mente, o projetista do espaço de trabalho indaga sobre o status do projeto de mudança, investigando o que está aberto a opções alternativas nas quatro dimensões, e o que parece estar definido. É importante ser crítico no que se refere ao que é declarado como definido pelos atores envolvidos. Frequentemente acontece de questões definidas poderem ser repensadas. $O$ modelo SOFT também indica que os atores relevantes sejam considerados participantes nas atividades de intervenção. Nessa fase, o projetista do espaço de trabalho está negociando com os membros da organização sobre o objetivo da intervenção, os recursos a serem colocados na intervenção, quem deve participar, e como insights e resultados da intervenção serão transmitidos e mantidos no projeto de mudança sócio-técnica em andamento.

130 projetista do espaço de trabalho tem que adquirir um entendimento básico do sistema de trabalho na organização ou na parte relevante da organização em questão. 0 caso aqui é entender as condições básicas do sistema de produção e as práticas e condições de trabalho. Também inclui ter uma idéia do que está sendo debatido no sistema de trabalho, quais são as questões atuais a serem resolvidas nas relações trabalhadores/gerência? Obter esse entendimento pode ser um processo concomitante à negociação das condições para a encenação.

Baseadas na experiência adquirida em dois casos, as intervenções tiveram um formato geral similar. Este foi um formato que consistiu de uma série de workshops com períodos intermediários de trabalhos de casa. Uma série de workshops precisa ser coerente para garantir que os participantes vejam que estão indo em direção a um certo objetivo. O processo e o resultado esperado da série de workshops devem ser apresentados aos participantes antes do seu início. Ao mesmo tempo, devido ao contexto organizacional particular e ao progresso do projeto sócio-técnico, o projetista do espaço de trabalho deve estar preparado para navegar. Em nosso segundo estudo de caso, um escritório de administração pública, atores do projeto de mudança aceleraram inesperadamente o processo de projetar novos escritórios de espaço aberto. Isso forçou a equipe do WSD a propor um ajuste na série planejada de workshops para acompanhar esta aceleração. Outra experiência geral na fase de intervenção é a de que ter duas atividades gerais parece funcionar bem : primeiro, usando ferramentas e métodos que visam a dar início a uma investigação colaborativa nas atuais prática e local de trabalho ; segundo, usando ferramentas e métodos direcionados para a prática e o local de trabalho futuros como um resultado do projeto de mudança sócio-técnica. Na segunda atividade, parece proveitoso enfatizar a noção de 'laboratório'. Os participantes dos workshops investigam diversas possibilidades futuras, conduzindo experimentos com o futuro local de trabalho (Binder, 2007).

15 Após a apresentação do estudo de caso do produtor industrial, o modelo na Figura 2 será usado para demonstrar a navegação do WSD e a intervenção neste contexto particular.

\section{0 caso do produtor industrial}

16 A empresa produz as assim chamadas luvas para a renovação da tubulação, especialmente tubulação de esgotos. $O$ processo chave para a empresa é a impregnação de meias com misturas químicas que permitem que endureçam quando instaladas na tubulação. A mistura de produtos químicos em diferentes composições acontece em 
processos por lotes, localizados na unidade de mistura. 0 sistema de produção requer muita manipulação manual de barris e sacos por 4-5 operadores. A exposição a vapores e poeira também faz parte do ambiente de trabalho, que é considerado problemático por todas as partes envolvidas na empresa.

O projeto de mudança sócio-técnica foi iniciado pela gerência de produção e pela organização de segurança da empresa. Em diferentes contextos, o motivo para iniciar o projeto foi declarado como sendo um dos seguintes, ou a combinação de ambos : 1) a capacidade de produção tinha de ser aumentada devido ao um crescente número de pedidos ; e 2) a instalação de produção atual sofreu com problemas severos no ambiente de trabalho. A empresa contratou dois engenheiros de projeto externos como consultores. Eles primeiro trabalharam em um projeto de substituição da atual tecnologia de lotes por uma nova. Durante seu trabalho, entretanto, eles identificaram um fornecedor de máquinas alemão que era capaz de desenvolver maquinário de trabalho contínuo para o processo de mistura. Foi subsequentemente decidido que eles deveriam optar por essa solução, e os dois engenheiros de projeto elaboraram uma especificação dos requisitos para esse maquinário. 0 novo sistema de produção seria um sistema fechado com entrada automática de matérias primas, melhorando, dessa forma, consideravelmente alguns aspectos do ambiente de trabalho.

No momento da intervenção do WSD, a nova máquina de mistura já estava especificada e encomendada. Durante o processo de construção da máquina, o fornecedor estava participando em seu próprio workshop. Os engenheiros de projeto tinham feito duas propostas para o layout do hall de produção vazio, onde o novo maquinário seria instalado. Ambas as propostas foram baseadas na otimização da tubulação na nova instalação, porque o comprimento dos canos poderia ser um fator crítico devido ao risco de enrijecimento da matéria prima dentro da tubulação. 
A Tabela 1 dá uma visão geral das atividades do WSD nesse caso, mostrando as três fases nas quais a equipe do WSD estava navegando

\begin{tabular}{|c|c|}
\hline Fase & Actividade \\
\hline Negociando as condiçōes & $\begin{array}{l}\text { Duas reuniões com o gerente de projeto. Assinatura de um } \\
\text { acordo de colaboração. }\end{array}$ \\
\hline Sistema de trabalho & $\begin{array}{l}\text { Classificação do ambiente de trabalho através do walk-through } \\
\text { da equipe do WSD na atual unidade de produçầ. }\end{array}$ \\
\hline Sistema de trabalho & $\begin{array}{l}\text { A equipe do WSD entrevista os operadores, o planejador de } \\
\text { produção e o gerente de produção. }\end{array}$ \\
\hline Negociando as condições & $\begin{array}{l}\text { Primeira reunião com a participação dos dois engenheiros de } \\
\text { projeto consultores. }\end{array}$ \\
\hline Sistema de trabalho & $\begin{array}{l}\text { Os membros da equipe do WSD fazendo um walk-through com } \\
\text { os operadores tirando fotos para um workbook (cadernos de } \\
\text { anotaçốs). }\end{array}$ \\
\hline Negociando as condiçōes & $\begin{array}{l}\text { Apresentação do plano de intervenção ao gerente de projeto e } \\
\text { engenheiros de projeto, e alocação de tarefas. }\end{array}$ \\
\hline Intervenção: Workshop 1 & $\begin{array}{l}\text { Apresentação dos workbooks. logo de projeto de layout baseado } \\
\text { na proposta dos engenheiros de projeto (sala de reunião). }\end{array}$ \\
\hline Trabatho de casa & Os operadores projetam seu layout. \\
\hline Intervenção: Workshop 2 & $\begin{array}{l}\text { Jogo de projeto de layout baseado na proposta dos operadores } \\
\text { (sala de reuniäo). }\end{array}$ \\
\hline Negociando as condiçốes & $\begin{array}{l}\text { Reuniäo com o coordenador do OHS e com o planejador de } \\
\text { produçăo sobre o planejamento dos cenários de uso. }\end{array}$ \\
\hline Sistema de trabalho & $\begin{array}{l}\text { Reunião com o gerente de projeto e com o coordenador do } \mathrm{OHS} \text {. } \\
\text { Identificaçăo de incidentes no atual sistema de produção. }\end{array}$ \\
\hline Intervenção: Workshop 3 & $\begin{array}{l}\text { Cenário de uso com foco nos procedimentos de trabalho, maqui- } \\
\text { nário e layout (hall de produģăo). }\end{array}$ \\
\hline Trabalho de casa & Contato com o fornecedor da máquina. \\
\hline Intervenção: Workshop 4 & $\begin{array}{l}\text { Cenário de uso com foco nas condiçōes do OHS na nova instala- } \\
\text { ção (hall de produção). }\end{array}$ \\
\hline & \\
\hline
\end{tabular}

\section{Preparando o cenário}

Ao iniciar o projeto do WSD, tivemos dificuldades em recrutar empresas que estivessem querendo servir de casos experimentais. A empresa de produção industrial foi recrutada devido a uma das consultoras do OHS que estava na equipe. Seu marido tinha um emprego na corporação que possuía a empresa. Ela lhe deu um panfleto descrevendo o projeto do WSD. Ele, por sua vez, deu esse panfleto para o coordenador de segurança e saúde da empresa. O coordenador do OHS, então, contatou o gerente do projeto do WSD e uma reunião foi agendada. Os participantes foram : o gerente do projeto do WSD e um dos consultores do OHS, o coordenador do OHS da empresa e o gerente de produção, que era também o gerente do projeto tecnológico. Pouco tempo depois dessa reunião, uma nova reunião aconteceu devido a certa incerteza na equipe do WSD sobre a empresa em questão ser um caso apropriado. Alguns membros da equipe estavam receosos porque muitas decisões já tinham sido tomadas, deixando apenas um espaço limitado para a intervenção. Desta vez a reunião foi entre um consultor do Instituto Tecnológico Dinamarquês e o consultor do OHS da primeira reunião. A agenda era para esclarecer o status atual do projeto de mudança sóciotécnica, bem como expectativas e necessidades mútuas. A reunião resultou em um acordo de colaboração formal. 0 acordo declarava que a empresa receberia assistência para garantir as melhores condições de trabalho possíveis na nova instalação e para permitir a participação e envolvimento dos trabalhadores no processo. $O$ acordo também determinava que um contato entre o fornecedor do maquinário e o projeto do WSD seria estabelecido. Por outro lado, o acordo garantia ao projeto do WSD os "direitos" das ferramentas e métodos experimentais, e a disseminação dos resultados. 0 
objetivo geral das atividades do WSD na empresa ficou definido: “...garantir uma modelagem holística de locais de trabalho novos ou reprojetados que sejam saudáveis para os empregados e eficazes para a empresa".

A equipe do WSD, representada pelo consultor do OHS, apresentou um planejamento de dois workshops que deveriam focar no layout do novo hall de produção. Esse foi o resultado das investigações dentro do processo de mudança sócio-técnica na empresa. $\mathrm{Na}$ equipe do WSD tivemos discussões sobre os assuntos "abertos" e "fechados" no processo de mudança. A nova máquina estava sendo construída nas oficinas do fornecedor alemão, e isso parecia ser uma questão definida no sentido de que seria difícil mudar as especificações e alterar a máquina. Mas o layout do hall de produção vazio parecia aberto a alternativas. Os dois engenheiros de projeto tinham feito duas propostas para o layout, mas nada estava decidido. o planejamento foi apresentado ao gerente de projeto e ao coordenador do OHS, e nós requisitamos que o gerente do projeto incluísse os dois engenheiros de projeto nos workshops. 0 gerente de projeto concordou em incluí-los.

\section{Sistemas de trabalho}

21 A fim de se obter um insight do sistema e ambiente de trabalho da empresa, a equipe do WSD fez um walk-through com os operadores e o representante de segurança da unidade de mistura (classificação do ambiente de trabalho). A isso se seguiram as entrevistas com os operadores, o planejador de produção e o gerente do projeto, a respeito do trabalho no atual sistema de produção, incluindo acidentes em que tenham tido que atuar. Finalmente, a equipe do WSD fez um walk-through com os operadores e uma câmera digital. Os operadores foram orientados a fotografar o sistema de produção baseados no seguinte código: coisas que são consideradas problemáticas e que, portanto, não deveriam ser transferidas para o novo sistema de produção (vermelho), coisas que funcionam bem e deveriam ser mantidas no sistema (verde), e coisas que precisam de atenção (amarelo). Doze fotos foram então selecionadas para um workbook. O workbook foi colocado na sala de controle por um período de uma semana. Nesse período os operadores fizeram comentários sobre as fotos usando o código de cores nos desenhos e textos. Workbooks similares foram preparados pelo representante de segurança e pelo consultor do OHS.

\section{Intervenções}

22 A intervenção da equipe do WSD foi realizada em dois eventos colaborativos, cada um consistindo em dois workshops. Cada workshop teve a duração de aproximadamente três horas. Os eventos foram jogos de projeto (Horgen et al., 1999 ; Johansson et al., 2002 ; Brandt \& Messeter, 2004) com o objetivo de negociar as condições do encontro entre a gerência de produção, dois engenheiros de projeto e três trabalhadores da unidade de mistura. $\mathrm{O}$ formato do jogo de projeto foi feito de modo a facilitar o processo de projeto colaborativo entre esses atores. No primeiro evento, os workshops foram direcionados para o layout da nova unidade, na qual a nova máquina de mistura seria instalada. No segundo evento, os dois workshops foram organizados como cenários de uso, destinados a estimular processos de trabalho e ergonomia na nova instalação. 


\section{O jogo de projeto de layout}

O primeiro evento foi um jogo de projeto de layout que aconteceu em uma sala de reunião da empresa. Para começar o workshop, os workbooks foram apresentados pelo consultor do OHS, pelo representante de segurança e pelos operadores, de modo a dar um panorama dos problemas conhecidos, mas também até então não identificados. Assuntos importantes foram acrescentados como 'observações' compiladas em um quadro colocado na parede na forma de um pôster. Em seguida, os engenheiros de projeto apresentaram brevemente como a nova máquina estava trabalhando.

Figura 3 : 0 jogo de projecto de layout

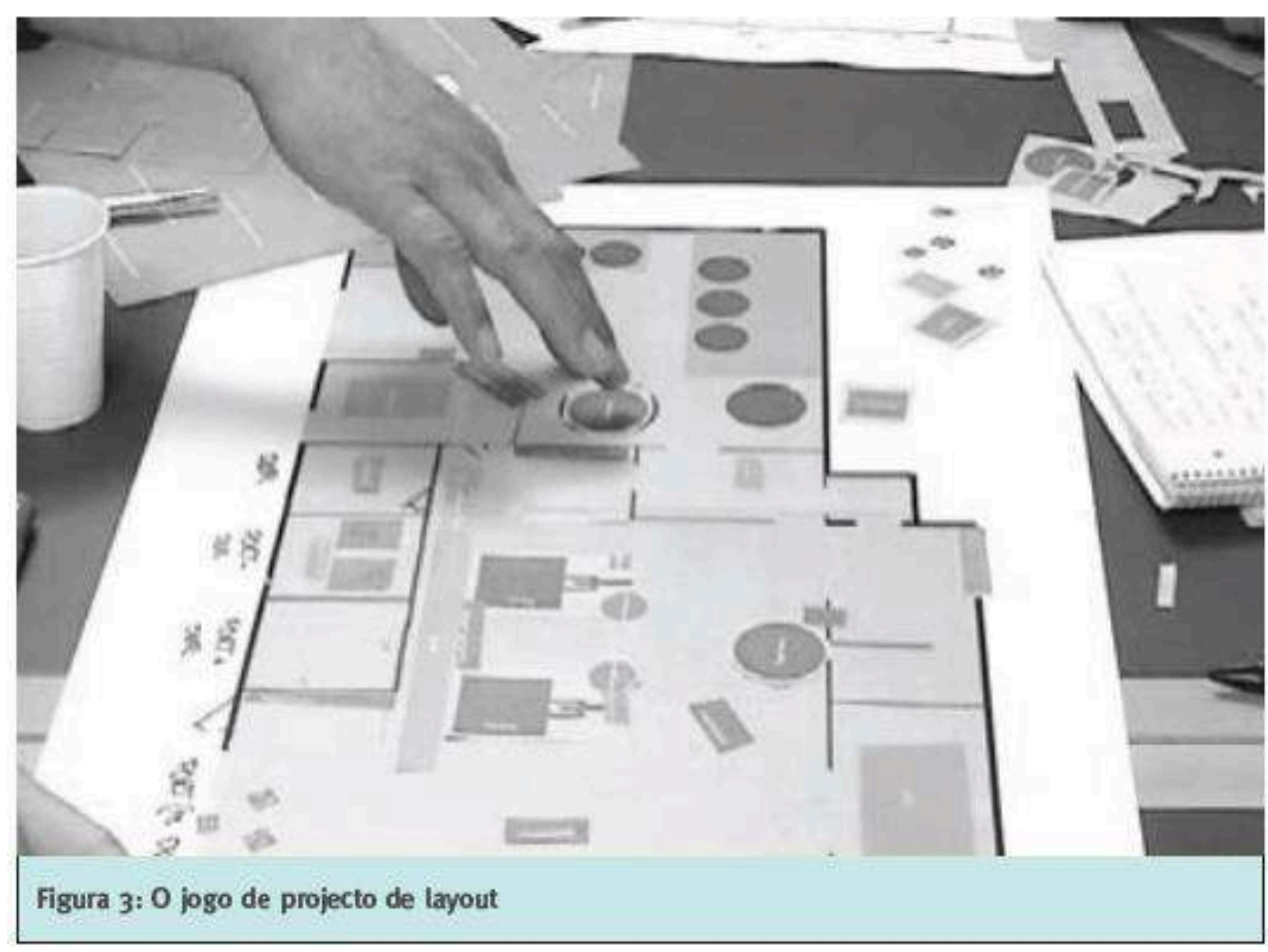

A equipe do WSD tinha preparado tabuleiros e peças de jogo. Durante os dois workshops, os participantes estavam sentados ao redor de um tabuleiro de jogo colocado no meio da mesa (Figura 3). 0 tabuleiro de jogo era um croqui da planta baixa da unidade de mistura existente e do hall adjacente, no qual a nova máquina de mistura deveria ser colocada. Pedaços de cartão colorido representavam diferentes artefatos da unidade. Um membro da equipe do WSD foi designado como mediador do jogo, e instruiu os participantes sobre o propósito do jogo de projeto : iniciar um processo colaborativo de projeto do layout da nova unidade de mistura. Ele também reforçou a idéia de que o workshop era uma espécie de 'laboratório', no qual os participantes teriam a oportunidade de explorar diferentes possibilidades de layout.

No primeiro workshop, o tabuleiro do jogo foi baseado na proposta de layout dos engenheiros de projeto. Esse layout estava impresso no tabuleiro e não era móvel. As peças coloridas do jogo representavam diferentes questões em relação ao projeto do espaço de trabalho, tarefas e equipamentos. Elas eram preenchidas pelos participantes durante o jogo. Dessa forma, todos os participantes poderiam fazer indagações sobre a 
proposta dos engenheiros de projeto, e este procedimento resultou em um número de propostas de possíveis soluções para problemas identificados. Ao final do workshop um trabalho de casa foi estabelecido para o segundo workshop. Os engenheiros de projeto deveriam checar algumas das características da máquina, o gerente de produção e o coordenador do OHS deveriam investigar a regulamentação sobre fogo e produtos químicos, e, finalmente, o gerente de produção sugeriu que os operadores deveriam trabalhar em uma nova proposta para o layout.

o segundo workshop começou com relatórios do gerente de produção e dos engenheiros de projeto sobre o seu trabalho de casa. Em seguida, os operadores apresentaram sua proposta de layout passo-a-passo em um tabuleiro de jogo com peças de jogo móveis, cada uma representando máquinas e equipamentos. Durante o jogo eles explicaram suas razões e idéias, e um processo de projeto colaborativo se iniciou. Ao final, o tabuleiro de jogo representava um layout incluindo muitas das propostas dos operadores. Contudo, durante esse processo colaborativo, outras coisas tinham sido alteradas.

Em resumo, o resultado do jogo de projeto de layout foi uma proposta de layout para a nova unidade de mistura, que era bastante diferente das duas propostas feitas originalmente pelos dois engenheiros consultores. A experiência prática de trabalho $\mathrm{e}$ as idéias trazidas pelos trabalhadores tiveram uma profunda influência na nova proposta para o layout, além de incluírem importantes aspectos ergonômicos. Os trabalhadores puderam trazer à tona coisas que não tinham sido consideradas pelos engenheiros de projeto. Funções de apoio, tais como manutenção e estoque, não haviam sido consideradas pelos engenheiros e, no entanto, tais funções eram parte do novo projeto de layout. O produto físico do jogo de projeto de layout foi o tabuleiro do jogo com uma planta baixa na qual as peças de papelão, que ilustravam a máquina e outros artefatos, foram colocadas em novas posições (Figura 4). 
Figura 4 : 0 tabuleiro de jogo de layout

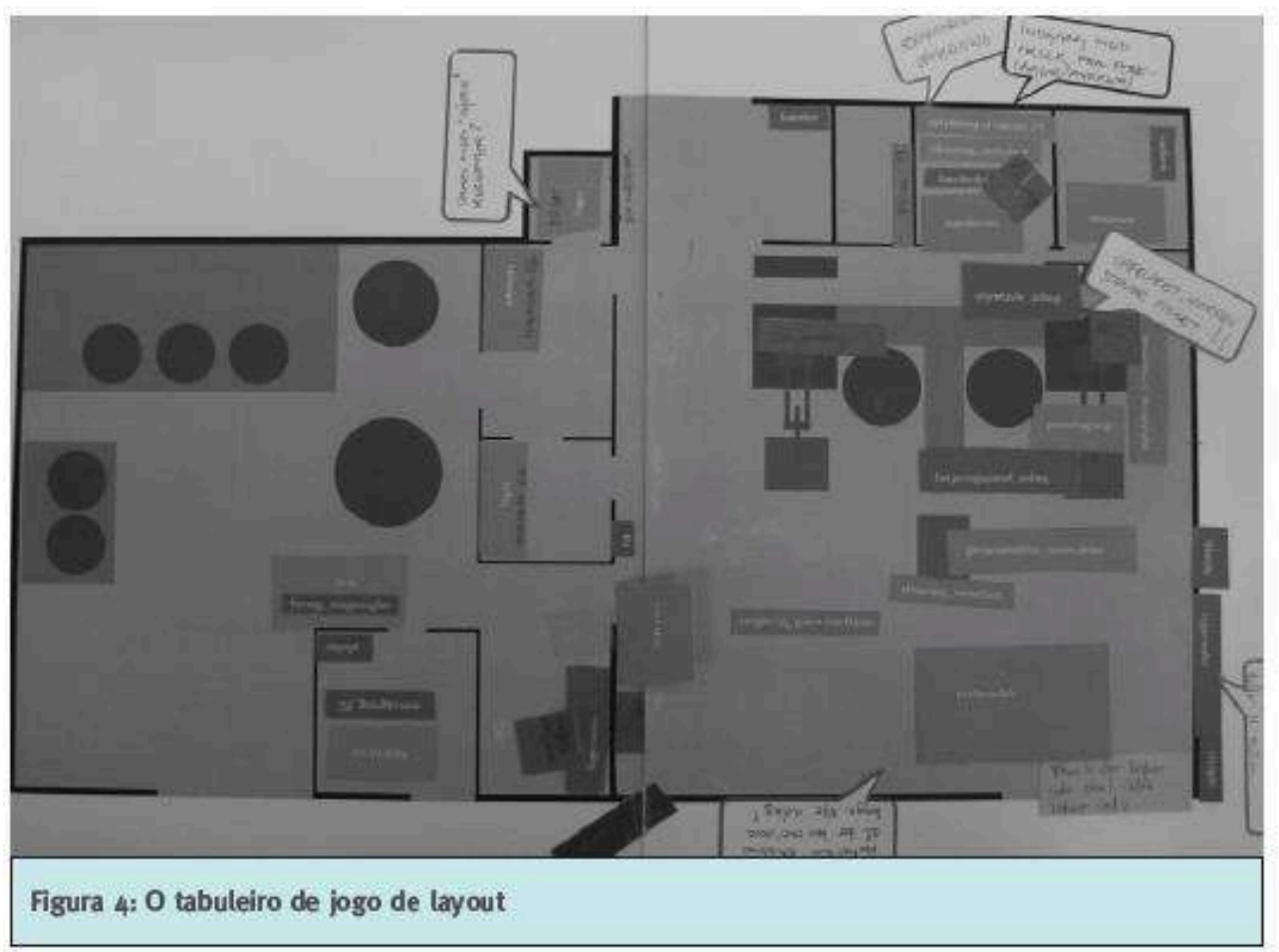

\section{Os workshops de cenário de uso}

Em um segundo evento colaborativo, um cenário de uso foi usado pela equipe do WSD. A idéia era explorar mais de perto a ergonomia e a prática de trabalho futuro relacionadas com a operação da nova máquina de mistura no ambiente projetado durante os workshops de layout. Isso foi feito através da simulação de processos de trabalho futuros através de cenários acontecendo no hall vazio designado para a nova unidade de mistura. A equipe do WSD produziu dois artefatos para facilitar o cenário de uso. O primeiro foi um modelo da nova unidade em escala 1:20 com representações móveis de máquinas e instrumentos (Figura 5). O segundo foi a colocação de marcadores em fita no chão, representando as máquinas e as novas paredes no hall vazio, de acordo com os resultados do jogo de layout. 0 modelo em escala foi colocado sobre uma mesa no hall vazio, e os cenários de uso começaram com os participantes em pé ao redor do modelo. Ao mesmo tempo, era possível mover-se pela nova unidade de mistura ao olhar os marcadores de fita no chão. Dois tipos diferentes de cenários de uso foram usados pela equipe do WSD. Em ambos os casos os participantes foram o gerente de produção, os dois engenheiros consultores, e três trabalhadores da unidade de mistura. Um membro da equipe do WSD foi o moderador do jogo.

\section{Cenário de uso com cartões de ocorrência}

29 No primeiro cenário de uso, o gerente de produção e os trabalhadores foram solicitados pelo moderador do jogo do WSD a passar por todo o processo do que seria esperado ser um cenário normal de produção com a nova máquina. Isso foi feito com o modelo em escala que foi fornecido. A equipe do WSD também preparou cartões de ocorrências, 
onde incidentes reais da produção estavam descritos. Esses eventos tinham sido identificados através das entrevistas com os trabalhadores e a gerência de produção, e estavam baseados na experiência adquirida na operação da unidade de mistura existente. Um exemplo é a seguinte instrução : "Você começou o processo de limpeza semanal. De repente você descobre um vazamento em uma válvula. Aproximadamente 5 litros de fluido derramaram no chão e ainda está vazando. 0 odor é de um solvente orgânico. O que você faz ?" A idéia foi abrir para um questionamento colaborativo sobre como os eventos atuais de produção poderiam ser tratados na nova unidade de mistura com uma máquina baseada em novos princípios. Os trabalhadores se alternavam pegando os cartões, e juntos discutiam como lidariam com o evento na nova instalação. Os demais participantes juntavam-se à reflexão aberta respondendo perguntas ou expressando seus pontos de vista. Os membros da equipe do WSD registraram continuamente em um flip-chart os problemas e idéias potenciais identificadas para resolvê-los. Durante essa sessão, o gerente de produção tomou uma decisão de projeto 'ali mesmo', porque ele percebeu que um tanque de vácuo precisava ser levado de uma sala para outra. Mais tarde, as informações nos flip-charts foram sistematizadas pela equipe do WSD em um documento que foi entregue a todos os participantes. Todos os itens dos flip-charts foram distribuídos em três categorias : o layout do hall, o sistema técnico e os procedimentos de trabalho. Os itens que necessitavam de uma investigação adicional também foram registrados, endo foram designadas as pessoas que ficariam responsáveis por esse trabalho de casa.

\section{O cenário de uso simulando a avaliação do local de trabalho}

O segundo cenário de uso aconteceu no mesmo local que o primeiro, com os mesmos participantes. Agora, o ambiente de trabalho e a ergonomia na nova unidade de mistura seriam investigados. O workshop foi conduzido pela equipe do WSD com o seguinte cenário : "A nova instalação vem funcionando há dois anos e hoje o consultor do OHS vem para uma visita para fazer uma avaliação do local de trabalho". Uma avaliação do local de trabalho é um mapeamento sistemático do ambiente de trabalho e é obrigatório segundo a lei dinamarquesa. 
Figura 5 : Cenário de uso no hall de produção

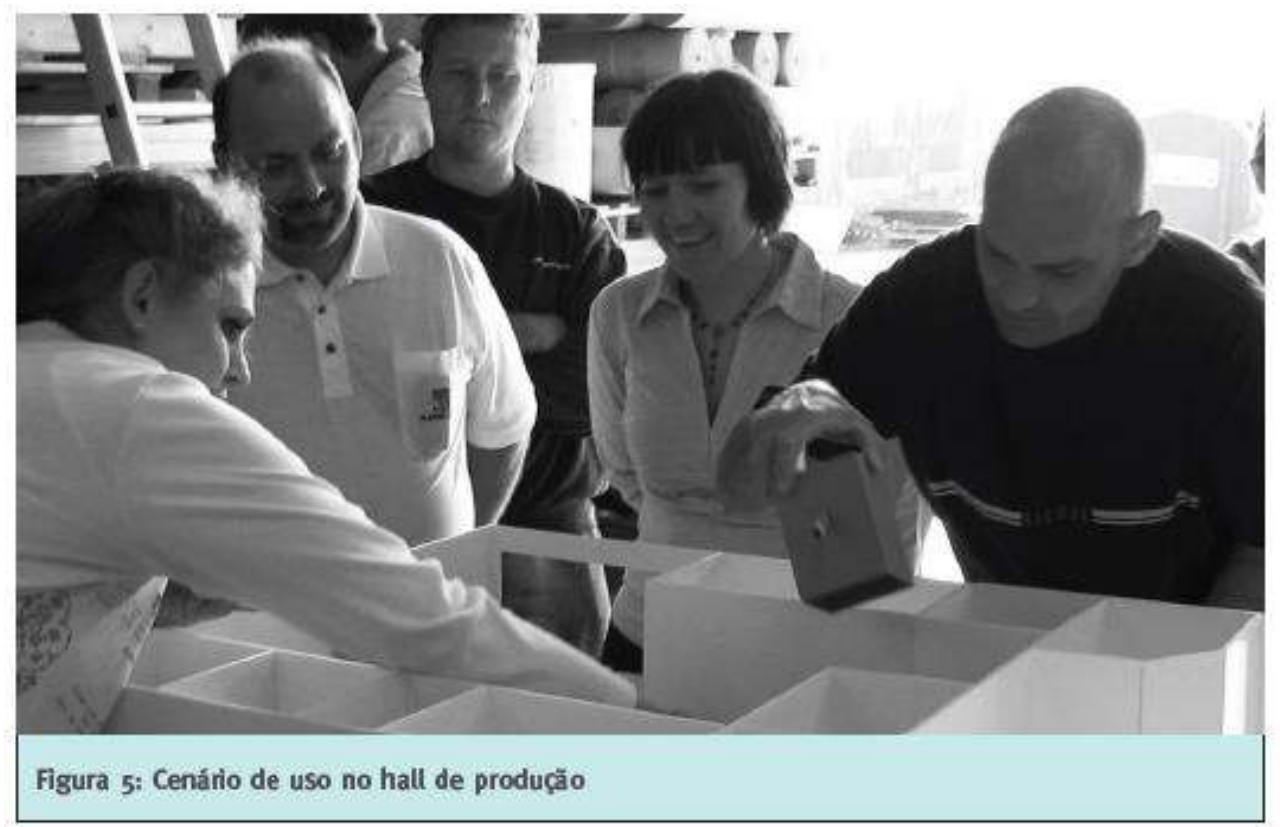

O consultor do OHS foi então levado pelos trabalhadores em um walk-through pela nova unidade (Figura 6). Isso foi feito movendo-se em torno das marcas de fita no chão e olhando para o modelo 3D em escala. Durante o tour, o consultor do OHS fez uma série de perguntas específicas sobre procedimentos de trabalho, projeto do local de trabalho, equipamento e proteção pessoal. Todos os participantes refletiram abertamente sobre essas questões. Problemas e idéias em potencial visando soluções foram registrados pela equipe do WSD e, subsequentemente, sistematizados em um documento que foi entregue a todos os participantes. Dessa vez os itens foram categorizados em relação aos espaços da nova unidade de mistura, por exemplo : a sala de controle, a sala de mistura, a sala de estoque de produtos químicos. Baseado nas duas seções dos cenários de uso, o gerente de produção fez diversas mudanças na especificação das necessidades para a nova instalação. Um tanque de vácuo foi transferido de uma sala para outra e foi solicitado que o fornecedor da máquina modificasse um detalhe, permitindo a mistura de aditivos durante a operação da máquina. Em uma avaliação dos workshops, o gerente de produção declarou: Estou certo que economizamos muitos recursos fazendo a coisa dessa maneira. Do contrário, teríamos que fazer mudanças a posteriori. O consultor do OHS disse : No geral, foi uma ótima sessão. Foi fantasticamente eficaz vislumbrar o futuro sistema de produção e o trabalho nele. Os trabalhadores estavam muito mais engajados, talvez porque havia a expectativa de sua contribuição. 
Figura 6 : Simulação da avaliação do local de trabalho no hall de produção

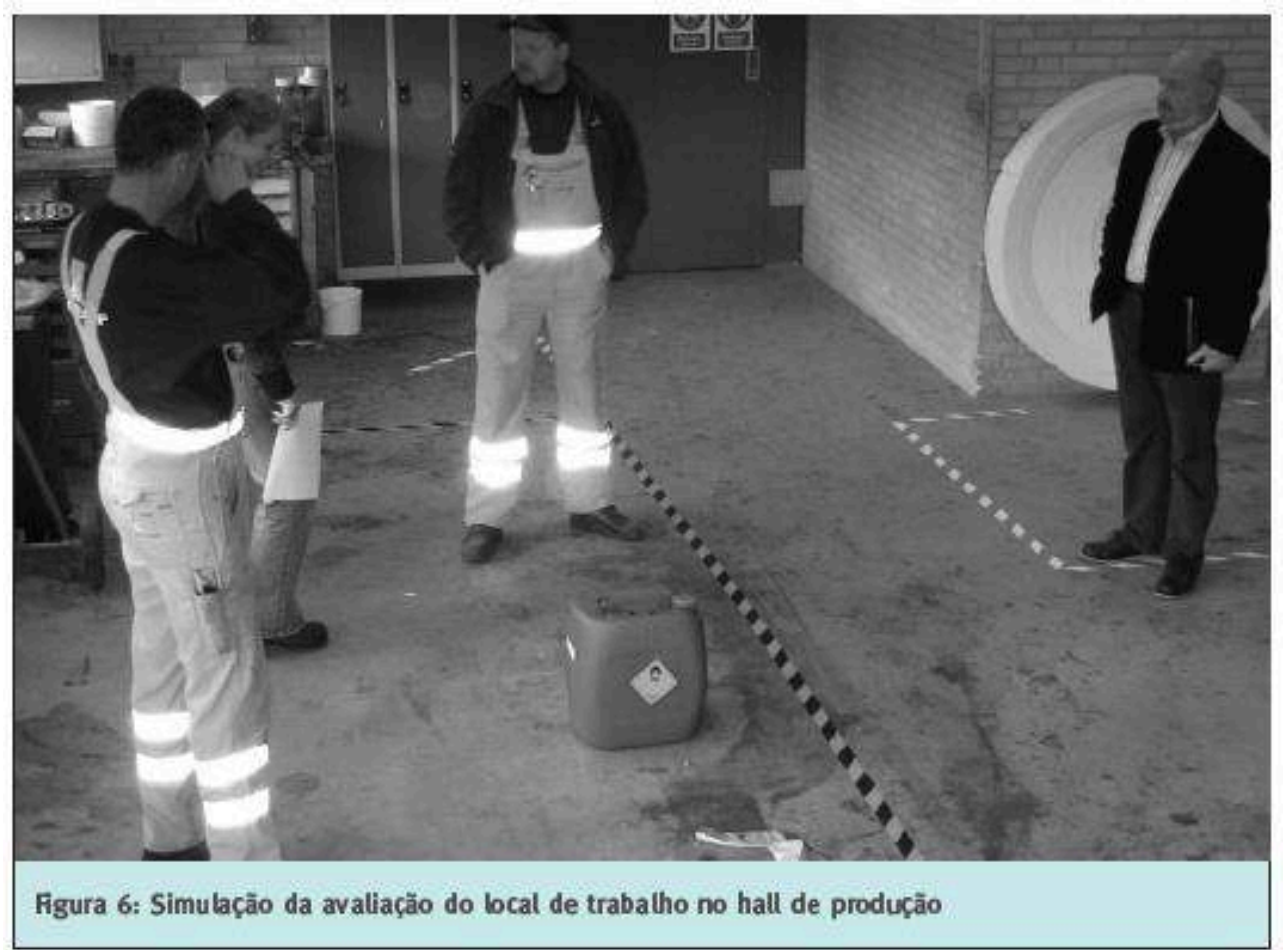

\section{As contribuições do WSD para o processo de mudança sócio- técnica}

Como as sessões dos workshops do WSD contribuíram para o projeto de uma nova linha de produção na unidade de mistura ? Como mencionado na introdução, o experimento do conceito do WSD pode ser visto como uma intervenção na concepção do projeto tecnológico para promover uma tecnologia mais humanista (Badham et al., 2001; Garrety \& Badham, 2004). A teoria da rede de contatos entre os atores (ANT - ActorNetwork Theory) oferece um suporte para o entendimento de como novos objetos sócio-tecnológicos chegam a ser construídos ou montados. A ANT foca em tecnologia no fazer (Latour, 1987). Dentro desse esquema, a concepção dos projetos tecnológicos é entendida como um processo de mudança das redes de relacionamento sócial e técnico. O papel dos projetistas da tecnologia é discutido através da introdução do conceito de "roteiro" (Akrich, 1992). Quando engenheiros estão projetando uma máquina ou um sistema de produção, eles desenvolvem hipóteses sobre o contexto no qual a máquina ou o sistema serão utilizados. Eles definem usuários e prescrevem como os usuários se relacionam com a tecnologia. Como é dito por Akrich, "Uma grande parte do trabalho dos inovadores é a de "inscrever" essa visão do (ou prever sobre) mundo no conteúdo técnico do novo objeto. Chamarei o produto final deste trabalho de "roteiro" ou “cenário".» (Akrich, 1992, p. 208, tradução livre).

Isso se alinha com o conceito de "configurar o usuário". Configurar durante o processo de projeto inclui definir a identidade dos futuros usuários e estabelecer as restrições de suas prováveis ações futuras em relação ao objeto (Woolgar, 1991). Ambos os conceitos 
estão baseados na distinção entre o usuário projetado e o usuário real, e assim o projetista está trabalhando com diferentes representações do usuário.

Nesse caso específico, entretanto, a prática do conceito do WSD significou que os usuários reais estiveram envolvidos em inscrever suas visões da nova linha de produção no roteiro. Os dois engenheiros de projeto estavam com um roteiro em andamento que não era muito específico no que dizia respeito aos usuários da nova instalação de produção. Eles estavam mais concentrados em otimizar a tubulação, e assim o trabalho dos operadores não estava articulado. Dessa forma, é difícil dizer que a configuração do usuário havia sido considerada. Os engenheiros estavam projetando o sistema técnico e deixando as tarefas de trabalho sem identificação. Os jogos de projeto de layout, e posteriormente os cenários de uso, tornaram-se um reenquadramento do objeto do projeto no processo de projeto de engenharia, desenvolvendo, assim, um roteiro "mais forte", estabelecendo mais explicitamente as relações entre a nova máquina e os operadores. Trazer as práticas de trabalho dos operadores e as suas reflexões sobre a conduta no novo sistema ampliou o projeto do objeto, de modo a incluir um reprojeto da nova instalação de produção: procedimentos de trabalho, equipamentos, limpeza, manutenção e uma série de fatores do ambiente de trabalho. Isso contrastou com o trabalho original dos engenheiros de projeto, que haviam focado principalmente na tubulação e layout dos componentes técnicos.

Os cenários de uso exploraram o novo sistema de produção como um resultado do processo de projeto nos workshops de jogos de layout. A introdução dos cenários foi uma mistura de dois principais meios de simulação (Daniellou, 2006) : a simulação experimental, baseada em um protótipo, e a simulação narrativa, onde os participantes fizeram um relato oral das maneiras possíveis de realizar as tarefas futuras. 0 cenário de uso com os cartões de ocorrências provou ser um processo de questionamento colaborativo das características do novo sistema de produção somando-se ao roteiro. 0 uso dos cenários revelou as diferenças entre as tarefas dos trabalhadores e sua conduta (Daniellou, 2005). Os trabalhadores não estavam falando e refletindo sobre suas tarefas formais. Eles estavam falando sobre as dificuldades que podiam prever no novo sistema de produção, e estavam pensando alto sobre como lidar com esses problemas. Através da reflexão sobre a viabilidade da conduta, muitos fatores foram identificados ; fatores que os engenheiros de projeto e o gerente de produção não tinham considerado no projeto do novo sistema.

36 Como os workshops do WSD contribuíram para o processo de formação de um roteiro ? Em vez de trabalhar com representações de usuários, os projetistas estavam colaborando com os reais futuros operadores da instalação nos workshops do WSD. Visto sob uma perspectiva de sócio-aprendizado, os workshops contribuíram para formar um espaço temporário de aprendizagem, no qual os relacionamentos de poder do dia-a-dia, papéis de especialistas e processos de tomada de decisão ficaram de fora. A equipe do WSD estabeleceu regras para os workshops, às quais todos os participantes estavam atrelados. O espaço de aprendizagem também foi percebido como um laboratório no qual experimentos aconteceram. Os experimentos foram sobre um questionamento colaborativo sobre os desenhos iniciais dos engenheiros de projeto e, subsequentemente, um processo de projeto colaborativo da instalação de produção, baseado em inputs dos futuros operadores, engenheiros de projeto, gerência de produção e o consultor do OHS. Através dos jogos de projeto, a equipe do WSD conduziu a reunião e iniciou processos de aprendizagem mútua entre esses atores de diferentes 
dimensões do modelo SOFT. O tabuleiro e as peças do jogo, o modelo em escala e as marcações com fita no hall de produção funcionaram como "objetos intermediários" apropriados (Wenger, 2000), permitindo conexões utilizáveis entre diferentes práticas de trabalho. As regras dos workshops e esses instrumentos habilitaram múltiplas práticas para iniciar um processo de projeto colaborativo, porque os instrumentos podiam ser compreendidos e interpretados por todos os participantes. Mesmo o termo abstrato "espaço de aprendizagem" tornou-se bem tangível quando experimentamos o poder se instalar cenários de uso no hall de produção real. Um operador declarou : É realmente uma boa idéia juntar pessoas de diferentes departamentos em uma sala com tempo suficiente para discutir o projeto e o layout em profundidade. E a 'melhor parte' (ou a cobertura do bolo - the icing on the cake) ficou situada no hall de produção real em vez de em uma sala de reuniões. Os engenheiros de projeto, um deles um pouco relutantemente, também reconheceram o efeito dos workshops. Um deles declarou : 0 ponto inicial era otimizar a tubulação. Outras coisas estão agora em foco e a unidade ficará bem diferente do que foi projetado inicialmente.

\section{Dispositivos de transmissão entre workshops e o processo de projeto de engenharia}

37 Estabelecer um espaço de aprendizagem, ou laboratório, temporário foi importante para facilitar um processo de projeto colaborativo. No entanto, foi ainda mais importante que os resultados dos workshops tenham sido "transmitidos" para a vida diária na organização, de modo a entrar no processo de projeto de engenharia. Isso revelou que artefatos, como a versão final do tabuleiro do jogo de layout e a compilação sistemática de documentos, serviram como importantes "elementos transmissores". Esses artefatos contribuíram para a sustentação transparente de insights e idéias dos workshops para todos os participantes. $\mathrm{O}$ tabuleiro do jogo foi um produto do projeto colaborativo. Foi uma maneira de apoiar o que, ao final do workshop, foi um entendimento compartilhado do layout da nova unidade de mistura. O próprio gerente do projeto foi um importante "ator de transmissão". Ele usou os elementos transmissores para revisar o documento de especificação de necessidades e, fazendo isso, ele também fez a transformação final dos resultados do workshop em documentos organizacionais comuns no processo de projeto de engenharia.

38 Atendo-se à metáfora do laboratório, Latour (1987) cunhou o conceito de inscrições e dispositivos de inscrição no seu estudo de trabalho de laboratório, e a construção de fatos científicos (Latour, 1987; Latour \& Woolgar, 1979). Dispositivos de inscrição transformam pedaços de matéria em documentos escritos. Como dito por Latour e Woolgar :

39 Mais precisamente, um dispositivo de inscrição é qualquer item instrumental ou a configuração particular de tais termos que possam transformar uma substância material em uma figura ou diagrama que é diretamente utilizável por um dos membros do espaço do escritório (Latour \& Woolgar, 1979, p. 51, tradução livre).

Os elementos transmissores entre os workshops (laboratórios) e o processo de projeto de engenharia podem ser considerados como inscrições. Inscrições são imagens de diferentes tipos que foram tiradas de instrumentos de laboratório para aparecerem limpas, redesenhadas e apresentadas (Latour, 1987). Em nosso caso, inscrições foram necessárias para transformar insights, idéias e propostas dos workshops em detalhes 
que pudessem entrar no processo de projeto de engenharia. 0 tabuleiro do jogo de layout tornou-se essa 'inscrição', que foi utilizável para os atores no processo de projeto de engenharia. $O$ tabuleiro do jogo transformou experimentos de layout e projeto colaborativo entre os participantes em uma figura ou desenho. Essa figura foi colocada na empresa e era apontada, após os workshops, como o projeto da nova unidade de mistura. Depois de deixar o laboratório, a inscrição do tabuleiro do jogo entrou no que se poderia chamar de uma carreira política (Henderson, 1999). O modelo do tabuleiro do jogo entrou na rede de relacionamentos políticos da empresa, como uma representação visual da nova instalação, que pode ser usada pelos atores para angariar apoio para o projeto.

41 A equipe do WSD agiu como um instrumento de inscrição ao produzir inscrições (PostIt's, ilustrações, peças do jogo) dos workshops (o laboratório), que podem ser transferidas e entendidas no processo de projeto de engenharia. As sessões de workshops foram como que um laboratório, e instrumentos de inscrições foram necessários para prover um dispositivo visual dos resultados dos experimentos no laboratório. Os muitos processos que aconteceram no laboratório tiveram que ser parcialmente descontextualizados de forma a poder levá-los para fora do laboratório.

42 As inscrições dos cenários de uso foram compilações. Isso foi, no entanto, uma transformação das ilustrações e demais anotações registradas nos flip-charts durante os cenários. Esse texto foi analisado e categorizado pela equipe do WSD e compilado em uma representação esquemática. A equipe do WSD tornou-se o dispositivo de inscrição que registrou as atividades do workshop e as transformou em figuras na forma de compilações sistematizadas de necessidades do projeto. $O$ formato da compilação acabou por se ajustar bem ao modo de trabalhar da engenharia, na medida em que representava as necessidades e propostas do projeto em uma forma que o deixava detalhado para os engenheiros. No caso do tabuleiro do jogo de layout, essa inscrição foi construída pelos próprios participantes dos workshops como resultado de um processo de projeto colaborativo.

\section{Navegação do projetista do espaço de trabalho}

Nesse caso, a equipe do WSD tentou agir como um projetista do espaço de trabalho. A fim de entender a navegação necessária à pratica do conceito de projeto do espaço de trabalho, construímos o modelo na Figura 2. O modelo emergiu com base em nossa experiência prática em dois casos. Ao encenar o processo de concepção do local de trabalho, o projetista do espaço de trabalho tem que navegar em três diferentes fases.

Durante a negociação para a encenação, foi, nesse caso, importante que a empresa nos contatasse e solicitasse ajuda. Eles estavam motivados, parcialmente devido à pressão da Inspeção do Trabalho, parcialmente porque eles estavam genuinamente interessados em aprender como envolver os trabalhadores em projetos de mudança sócio-técnica. Para a equipe do WSD foi crucial que uma aliança com o gerente de produção, que era também o gerente do projeto de tecnologia, acontecesse desde o início.

A equipe do WSD propôs que o gerente de projeto focasse no layout em dois workshops, ao que ele concordou. A equipe solicitou que o gerente de projeto convidasse os dois engenheiros de projeto externos para participar dos workshops. Não tivesse o gerente feito essa aliança, teria sido mais difícil ter assegurada a sua participação. 0 gerente de projeto também concordou que as propostas dos engenheiros pudessem ser submetidas 
a uma reavaliação nos workshops. Além disso, o gerente de produção demonstrou o seu comprometimento ao revisar o documento de especificação das necessidades baseado nos resultados dos workshops.

A equipe do WSD estava navegando em benefício de um projetista de um espaço de trabalho projetado ; uma tarefa que no futuro pode ser a tarefa dos consultores do OHS. Uma das consultoras do OHS participante, subsequentemente, obteve uma nova posição como gerente de segurança e saúde ocupacional na empresa caso. Em uma entrevista, ela declarou :

“É um super-produto para um serviço de saúde ocupacional ganhar o mercado em relação a todos os tipos de mudanças em uma empresa. Em minha posição como gerente do OHS, eu engajaria um consultor para empregar os métodos do WSD. Eu penso que é importante ter outras pessoas para gerenciar o processo que não sejam os mesmos envolvidos no processo de mudança. Eu tenho recomendado fortemente os métodos a outros desde a minha participação. É uma maneira de envolver os trabalhadores de forma ativa."

\section{Conclusões} para o processo de projeto de engenharia. A equipe do WSD assumiu o papel de projetista do espaço de trabalho e, através do uso de métodos participativos em workshops, conseguiu um impacto tangível no projeto da tecnologia. O layout foi mudado, novos procedimentos de trabalho emergiram e as medidas relacionadas à ergonomia e ao ambiente de trabalho foram identificadas e especificadas entre as necessidades do projeto. $O$ projeto da tecnologia ainda não está implementado na empresa e, portanto, nós não podemos demonstrar o efeito do conceito do WSD. As plantas do projeto, entretanto, mudaram consideravelmente com a aceitação de todos os atores.

O objeto do projeto e, portanto, sua caracterização mudou: da focalização colocada sobre a tubulação e o layout dos componentes técnicos, passou-se a incluir os processos de trabalho, os procedimentos e fatores do ambiente de trabalho. No papel de projetista do espaço de trabalho, foi importante para a equipe do WSD se certificar de que as conquistas nos workshops fossem transmitidas e sustentadas no processo de projeto de engenharia. Nesse caso, os artefatos como o tabuleiro de jogo de layout e as compilações de idéias e necessidades oriundas dos cenários de uso serviram como dispositivos de inscrições e transmissão apropriados. Parece importante para o projetista do espaço de trabalho identificar inputs apropriados ao processo de projeto para que os resultados do workshop tenham possibilidade de impactar fortemente este processo de concepção.

Quando se estabelece o cenário e navega-se num contexto particular, a aliança entre a equipe do WSD e o gerente de produção foi de grande importância na sustentação e acompanhamento dos resultados do workshop.

No Programa de Projeto do Espaço de Trabalho, dois outros casos estão em andamento. Esperam-se, em breve, novas experiências e conhecimentos para nos apoiar, como pesquisadores, na prática de métodos participativos em processos sócio-técnicos de transformação. Esperamos também gerar conhecimentos sobre como esses métodos 
podem impactar os projetos de tecnologia a partir de uma perspectiva humanista, considerando o ambiente de trabalho. É de especial relevância evidenciar a relação entre a atividade de projeto colaborativo dos workshops e os processos de projetos desenvolvidos por especialistas em tecnologia. Ademais, é importante determinar até que nível de complexidade técnica é possível e apropriado usar os métodos e técnicas do WSD. Isso será investigado futuramente em novos estudos de caso. Finalmente, nesse caso foi fácil envolver os operadores nos workshops, apesar da dificuldade junto aos engenheiros de projeto. É importante encontrar caminhos e técnicas que encorajem os engenheiros de projeto a se envolverem em atividades de projeto colaborativas e, desta forma, contribuírem com experiências em seu domínio de conhecimento.

\section{BIBLIOGRAFIA}

Akrich, M. (1992). The description of technical objects. In W.E.Bijker

\& J. Law (Eds.), Shaping technology/building society : studies in sociotechnical change (pp. 205-224). Cambridge MA : MIT Press.

Badham, R., Garrety, K., \& Kirsch, C. (2001). Humanistic redesign and technological politics in organizations. Journal of Organizational Change Management, 14, 50-63.

Binder, T. (2007). Why Design : Labs? In Design Inquiries 2007, 2nd Nordic Design Research Conference. Stockholm : Sweden.

Brandt, E. \& Messeter, J. (2004). Facilitating collaboration through design games. In A. Clement (Ed.), Proceedings of the eighth conference on Participatory design : Artful integration : interweaving media, materials and practices Volume 1 (pp. 121131). New York: ACM.

Broberg, O. (2007). Integrating ergonomics into engineering : Empirical evidence and implications for the ergonomists. Human Factors and Ergonomics in Manufacturing, 17, 353-366.

Broberg, O. \& Hermund, I. (2004). The OHS consultant as a 'political reflective navigator' in technological change processes. International Journal of Industrial Ergonomics, 33, 315-326.

Daniellou, F. (2005). The French-speaking ergonomists' approach to work activity : crossinfluences of field intervention and conceptual models. Theoretical Issues in Ergonomics Science, 6, 409-427.

Daniellou, F. (2006). Simulating future work activity is not only a way of improving workstation design. In R. N. Pikaar, E. A.

P. Koningsveld, \& P. J. M. Settels (Eds.), Meeting Diversity in Ergonomics (pp. 5). Amsterdam : Elsevier.

Garrety, K. \& Badham, R. (2004). User-centered design and the normative politics of technology. Science, Technology, \& Human Values, 29, 191-212.

Greenbaum, J. \& Kyng, M. (1991). Design at Work : Cooperative Design of Computer Systems. Chichester : Lawrence Erlbaum Associates. Henderson, K. (1999). On Line and On Paper. Cambridge MA : The MIT Press. 
Horgen, T. H., Joroff, M. L., Porter, W. L., \& Schön, D. A. (1999). Excellence by Design : Transforming Workplace and Work Practice. New York : John Wiley \& Sons.

Jensen, C. B. (2006). The wireless nursing call system : Politics of discourse, technology and dependability in a pilot project. Computer Supported Cooperative Work, 15, 419-441.

Johansson, M., Fröst, P., Brandt, E., Binder, T., \& Messeter, J. (2002). Partner engaged design : New challenges for workplace design. In New Challenges For Workplace Design, Participatory Design Conference 2002. Malmö, Sweden.

Latour, B. (1987). Science in action. Cambridge MA : Harvard University Press.

Latour, B. \& Woolgar, S. (1979). Laboratory life : The construction of scientific facts. Princeton : Princeton University Press.

Wenger, E. (2000). Communities of practice and social learning systems. Organization, 7, 225-246.

Woolgar, S. (1991). Configuring the user : the case of usability trials. In J.Law (Ed.), A Sociology of Monsters (pp. 57-99). London : Routledge.

\section{NOTAS}

1. Utilizadores

\section{RESUMOS}

O programa de pesquisa sobre Projeto de Espaços de Trabalho (WSD - Workspace Design) da Dinamarca visa desenvolver e experimentar um novo conceito em potencial para ergonomistas e outros consultores do local de trabalho envolvidos em processos sócio-técnicos de projeto. 0 objetivo deste trabalho é relatar a experimentação desse conceito num caso envolvendo o projeto e a implementação de uma nova tecnologia em instalação industrial. 0 caso mostrou como o conceito do WSD pode contribuir para um processo de projeto de engenharia. A equipe do WSD assumiu o papel de projetista do espaço de trabalho e, através de workshops participativos, contribuiu para o projeto tecnológico. 0 diálogo entre usuários e engenheiros de projeto foi facilitado por objetos intermediários, tais como workbooks (cadernos de anotações), tabuleiros do jogo de layout e modelos 3D em escala. No papel de projetista do espaço de trabalho, era importante que a equipe do WSD assegurasse que os resultados dos workshops fossem "transmitidos" e mantidos no processo de projeto de engenharia. Nesse caso, constatou-se que artefatos como o tabuleiro do jogo de layout e documentos contendo compilações de idéias e necessidades oriundas dos cenários de uso serviram como dispositivos de transmissão dos resultados ou inscrições das questões discutidas.

El programa de pesquisa sobre Proyecto de Espacios de Trabajo (WSD - Workspace Design) de Dinamarca visa desarrollar y probar un nuevo concepto en potencial para ergónomos y otros consultores del lugar de trabajo involucrados en procesos socio-técnicos de proyecto. El objetivo de este trabajo es relatar la experimentación de ese concepto en un caso envolviendo el proyecto y la implementación de una nueva tecnología en instalación industrial. El caso mostró como el 
concepto del WSD puede contribuir para un proceso de proyecto de ingeniería. El equipo del WSD asumió el papel de proyectista del espacio de trabajo y, a través de talleres participativos, contribuyó para el proyecto tecnológico. El diálogo entre usuarios e ingenieros de proyecto fue facilitado por objetos intermediarios, tales como workbooks (cuadernos de anotaciones), tableros del juego de layout y modelos 3D en escala. En el papel de proyectista del espacio de trabajo, era importante que el equipo del WSD asegurase que los resultados de los talleres fuesen "transmitidos" y mantenidos en el proceso de proyecto de ingeniería. En ese caso, se constató que artefactos como el tablero del juego de layout y documentos conteniendo compilaciones de ideas y necesidades oriundas de los escenarios de uso sirvieron como dispositivos de transmisión de los resultados o inscripciones de las cuestiones discutidas.

Le programme de recherche Danois de conception des espaces (WDS) développe et expérimente un nouveau concept potentiel pour les ergonomes et de manière générale pour tous les consultants qui sont engagés dans une approche sociotechnique de la conception. L'objectif de cet article est de rendre compte d'un cas durant lequel on a utilisé ce concept pour la conception et l'implantation d'une nouvelle technologie. L'équipe du WSD a pris un rôle de concepteur des espaces de travail, et à travers des ateliers participatifs a tenté d'avoir un impact sur la technologie. Les dialogues entre les utilisateurs et les ingénieurs étaient facilités par des objets frontières, tels que des ouvrages professionnels, des maquettes papiers (3D) et des maquettes volumétriques. Il était important pour les chercheurs du WSD d'être sûr que les propositions issues des ateliers participatifs soient "transmises" aux concepteurs et effectivement prises en compte dans la conception. Il s'est avéré que les artefacts et les documents qui compilaient les scénarios d'utilisation élaborés durant les ateliers participatifs ont été des médiateurs efficaces pour véhiculer les idées et les requêtes issues des ateliers participatifs.

The Danish Workspace Design (WSD) research program aims to develop and test a potential new concept for ergonomists and other workplace consultants who are to engage in socio-technical design processes. The objective of this paper is to report on the trial run of the workspace design concept in a case involving the design and implementation of a new mixing technology in an industrial plant. The case showed how the WSD concept can contribute to an engineering design process. The WSD team assumed the role of workspace designer and, through participatory workshops, achieved an impact on the technological project. The dialogue between users and design engineers was facilitated by intermediary objects such as workbooks, layout game boards, and 3D scale models. In the role of workspace designer, it was important for the WSD team to make sure that the achievements in the workshops were itransmittedî to and sustained in the ordinary engineering design process. In this case, it was found that artifacts such as a layout game board and documents with compilations of ideas and requirements from scenarios for use served as appropriate transmitting devices or as inscriptions of the discussed ideas.

\section{ÍNDICE}

Keywords: participatory design, workplace design, ergonomics, intermediary objects Mots-clés: conception participative, conception des espaces de travail, ergonomie, objets frontières

Palabras claves: proyecto participativo, proyecto de espacios de trabajo, ergonomía, objetos intermediarios

Palavras-chave: projeto participativo, projeto de espaços de trabalho, ergonomia, objetos intermediários 


\section{AUTORES}

\section{OLE BROBERG}

Department of Management Engineering, Technical University of Denmark Produktionstorvet DTU - Bygning 424, 2800 Kgs. Lyngby, Denmark ob@ipl.dtu.dk 